\title{
Postconcussion Symptoms in Patients with Injury-Related Chronic Pain
}

\author{
Britt Marie Stålnacke \\ Department of Community Medicine and Rehabilitation, Umeå University Hospital, Umeå University, Building 9A, \\ 90185 Umeå, Sweden \\ Correspondence should be addressed to Britt Marie Stålnacke, brittmarie.stalnacke@rehabmed.umu.se
}

Received 4 December 2011; Revised 19 March 2012; Accepted 19 March 2012

Academic Editor: Brian D. Greenwald

Copyright ( 2012 Britt Marie Stålnacke. This is an open access article distributed under the Creative Commons Attribution License, which permits unrestricted use, distribution, and reproduction in any medium, provided the original work is properly cited.

\begin{abstract}
Background. Postconcussion symptoms (PCSs)—such as fatigue, headache, irritability, dizziness, and impaired memory-are commonly reported in patients who have mild traumatic brain injuries (MTBIs). Evaluation of PCS after MTBI is proposed to have a diagnostic value although it is unclear whether PCS are specific to MTBI. After whiplash injuries, patients most often complain of headaches and neck pain; the other PCS are not as closely evaluated. In patients with chronic pain because of other injuries, the presence of PCS is unclear. This study aimed to describe the frequency of PCS in patients with injury-related pain and to examine the relationships between PCS, pain, and psychological factors. Methods. This study collected data using questionnaires addressing PCS (Rivermead Postconcussion Questionnaire, RPQ), pain intensity (Visual Analogue Scale), depression, anxiety (Hospital, Anxiety, and Depression Scale), and posttraumatic stress (Impact of Event Scale). Results. Fatigue (90.7\%), sleep disturbance $(84.9 \%)$, headache $(73.5 \%)$, poor concentration $(88.2 \%)$, and poor memory $(67.1 \%)$ were some of the most commonly reported PCS. Significant relationships were found between PCS and posttraumatic stress, depression, and anxiety. Conclusion. To optimize treatment, it is important to assess each patient's PCS, the mechanism of injury, and factors such as posttraumatic stress and depression.
\end{abstract}

\section{Introduction}

The great majority (80-90\%) of traumatic brain injuries is classified as mild traumatic brain injury (MTBI)/concussion $[1,2]$. These injuries are a matter for general concern because of their potential long-term consequences-persistent post-concussion symptoms (PCSs). PCS include headache, fatigue, dizziness, and impaired memory. These symptoms can affect both work and leisure time [3-5]. Although the natural course of recovery after MTBI consists of restitution of many symptoms within three months after injury [6], a significant number of persons report PCSs that last for many months to even years after injury. Evaluation of these symptoms after MTBI can have diagnostic value. For patients with longterm symptoms, a diagnosis of postconcussion syndrome is sometimes used. According to the ICD10 criteria, at least three symptoms, which may include headache, dizziness, fatigue, depression, irritability, difficulty in concentration, and memory problems, are required for a diagnosis of postconcussion syndrome [7]. The DSM IV criteria for postconcussion disorder include evidence of three or more of these symptoms present for at least three months combined with signs of impaired cognitive function and social disability [8].

Whether PCS are specific to MTBI is unclear since symptoms commonly reported after MTBI have been reported in the general population and by patients with chronic pain. Some of the factors that have been found to contribute to the persistence of symptoms are depression and posttraumatic stress $[9,10]$.

Chronic pain is an acute and/or intermittent pain that persists more than three months [11], and the great majority of chronic pain is musculoskeletal pain. Apart from individual suffering, chronic pain is costly for society. Some of the most common causes of musculoskeletal pain are injuries related to traffic accidents, falls, and sports. 
In western countries, whiplash as the result of traffic accidents has a very high annual incidence: 1.0 to $3.2 / 1000$ per year [12]. Whiplash is an acceleration-deceleration mechanism of energy transferred to the neck that may result in soft tissue injury/distortion of the neck. Most studies of the long-term outcome of whiplash-associated disorder (WAD) have focused on neck pain and headache since these are the dominating complaints, while other PCSs are less investigated. Cognitive symptoms such as memory and concentration difficulties have been reported in patients with whiplash injuries, but the relevance of these symptoms has not been fully examined. Although some studies have shown neuropsychological dysfunction in persons with long-term cognitive symptoms after whiplash injury $[13,14]$, other studies have suggested neurotic development or preexistent stress as the underlying cause [15].

Although most studies suggest that female gender is a potential prognostic factor related to poor recovery both after MTBI [16] and whiplash injuries [17], some studies fail to show any gender differences regarding chronic symptoms as the result of MTBI and whiplash injuries $[6,18]$. For MTBI patients with PCS, some studies have divided the symptoms into three subgroups: emotional, cognitive, and physical $[19,20]$. For example, when comparing patients with chronic pain and patients with MTBI, Smith-Seemlier et al. found that cognitive difficulties were more often reported by the MTBI patients [19]. No group differences were found for total scores of postconcussion symptoms. Since their study focused on chronic pain patients regardless of the cause of pain, it may be of interest to study symptoms in patients with injury-related chronic pain.

The aims of the present study were (i) to describe the frequency of postconcussion symptoms in patients with injuryrelated chronic pain, (ii) to study the relationships between postconcussion symptoms and pain intensity, posttraumatic stress, and depression, (iii) and to examine gender differences regarding these variables.

\section{Patients and Methods}

A cross-sectional study design was used to study patients with chronic pain caused by an injury and referred by regional general practitioners to the Pain Rehabilitation Clinic at the Umeå University Hospital (Umeå, Sweden). The study included 86 patients - 59 women and 27 men (aged $41.1 \pm 10.3$ years). The participants suffered from pain caused by falls (14.0\%), whiplash injuries $(44.4 \%)$, other nonwhiplash traffic injuries sustained as the result of bicycle and motorcycle accidents $(8.1 \%)$, horseback riding $(8.1 \%)$, sports $(1.2 \%)$, assaults $(5.8 \%)$, and other injuries such as work-related injuries $(18.4 \%)$. For all patients, the time between injury and assessment was more than one year.

2.1. Assessments. During assessment in the clinic, the patients answered a set of questionnaires. Information about each participant's trauma history was collected from hospital records. Symptoms (pain intensity and whiplash-related symptoms) were assessed using the Visual Analogue Scale [21], the Rivermead Postconcussion Symptoms Questionnaire [22], the Impact of Event Scale [23], and the Hospital Anxiety and Depression Scale [24].

2.2. The Visual Analogue Scale. Pain intensity was rated using the Visual Analogue Scale (VAS) [21]. The scale consists of a $100 \mathrm{~mm}$ straight line with defined end points ("no pain" and "worst pain imaginable") on which the patients were asked to mark their experienced pain (results in mm). The VAS is considered to have a high degree of reliability and validity.

\subsection{Rivermead Postconcussion Symptoms Questionnaire. The} Rivermead Postconcussion Symptoms Questionnaire (RPQ) [22] is a validated instrument that was used to assess the frequency and severity of 16 symptoms that are commonly encountered postconcussion symptoms. The RPQ asks patients to rate the extent to which their symptoms (compared with their premorbid levels) have become more problematic over the previous 24 hours. The RPQ uses a rating scale with values $0-4$, from no problem at all to a severe problem. A total symptom score can be calculated as a sum of all scores (possible score 0-72) [22].

2.4. The Impact of Event Scale. The Impact of Event Scale (IES) is a widely used self-report scale [23]. It is a valid measure of posttraumatic stress reactions and has been suggested as a screening tool for posttraumatic stress disorder (PTSD). The IES comprises 15 statements: seven questions about intrusive symptoms and eight questions about avoidance symptoms. The patients answer the questionnaire regarding their symptoms during the last week. The total score, which varies between 0 and 80 , is divided into four stress reaction grades: subclinical (0-8), mild (9-25), moderate (26-43), and severe (44-80) [23].

2.5. HAD. To measure anxiety and depression, the Hospital Anxiety and Depression Scale (HAD) was developed and validated on nonpsychiatric medical patients [24]. The questionnaire comprises of 14 items divided in two parts, for rating of depression and anxiety. Each item has a four response category ranging between 0 and 3 . The scale ranges between 0 and 21 for both depression and anxiety. According to Zigmond and Snaith, the cut-off level for possible cases of anxiety disorder and depression is a score $\geq 8$ on each subscale [24].

2.6. Statistical Analyses. All statistical analyses were performed with SPSS for Windows (version 19.0). Data are reported as means \pm standard deviations unless indicated otherwise. Comparisons of populations were made using the Mann-Whitney $U$ test. Pearson's correlation coefficient was calculated for the analysis of bivariate correlations. Statistical significant level was set at 0.05 . 
TABLE 1: Frequency of occurrence of postconcussion symptoms (Rivermead Postconcussion Symptoms Questionnaire).

\begin{tabular}{|c|c|c|c|c|c|c|c|}
\hline & $\begin{array}{l}\text { All patients } \\
(n=86)(\%)\end{array}$ & Mean & $\begin{array}{c}\text { Women } \\
(n=59)(\%)\end{array}$ & Mean & Men $(n=27)(\%)$ & Mean & $P$ \\
\hline Headache & 73.5 & 2.25 & 51.0 & 2.21 & 40.72 & 2.33 & n.s. \\
\hline Dizziness & 61.7 & 1.70 & 40.0 & 1.65 & 34.9 & 1.81 & n.s. \\
\hline Nausea/vomiting & 29.1 & 1.01 & 30.0 & 1.09 & 16.3 & 0.85 & n.s. \\
\hline Sleep disturbance & 84.9 & 2.86 & 42.0 & 2.84 & 45.3 & 2.88 & 0.024 \\
\hline Fatigue & 90.7 & 3.01 & 57.0 & 3.18 & 53.5 & 2.67 & n.s. \\
\hline Irritability & 66.3 & 2.11 & 54.0 & 2.14 & 50.0 & 2.04 & n.s. \\
\hline Feeling depressed & 55.8 & 1.82 & 41.0 & 2.02 & 40.7 & 1.41 & n.s. \\
\hline Feeling frustrated & 55.8 & 1.93 & 40.0 & 2.03 & 44.5 & 1.70 & 0.046 \\
\hline Poor memory & 67.1 & 1.81 & 51.0 & 1.90 & 53.5 & 1.63 & n.s. \\
\hline Poor concentration & 88.2 & 2.01 & 50.0 & 2.21 & 52.3 & 1.59 & n.s. \\
\hline Noise sensitivity & 59.5 & 1.52 & 45.0 & 1.87 & 34.9 & 1.87 & n.s. \\
\hline Blurred vision & 55.8 & 1.05 & 31.0 & 0.96 & 32.6 & 1.22 & 0.001 \\
\hline Sensitivity to light & 51.2 & 1.31 & 41.0 & 1.35 & 44.2 & 1.22 & n.s. \\
\hline Double vision & 26.2 & 0.44 & 13.0 & 0.40 & 16.3 & 0.52 & n.s. \\
\hline Restlessness & 69.0 & 1.37 & 35.0 & 1.37 & 48.8 & 1.37 & n.s. \\
\hline $\begin{array}{l}\text { Taking longer to } \\
\text { think }\end{array}$ & 74.1 & 1.05 & 41.0 & 1.83 & 48.8 & 0.85 & 0.005 \\
\hline Total score (mean) & & 27.32 & \multicolumn{2}{|c|}{28.33} & \multicolumn{2}{|c|}{25.15} & n.s. \\
\hline
\end{tabular}

TABLE 2: Proportion of patients reporting symptoms and symptoms scores (\%).

\begin{tabular}{|c|c|c|c|c|c|c|}
\hline Symptom scores & $\begin{array}{c}0 \text { (not experienced } \\
\text { symptom) }\end{array}$ & $\begin{array}{c}1 \text { (no longer a } \\
\text { problem) }\end{array}$ & 2 (mild problem) & $\begin{array}{l}3 \text { (moderate } \\
\text { problem) }\end{array}$ & 4 (severe problem) & 2-4 (problem) \\
\hline Headache & 14.5 & 16.9 & 21.7 & 22.9 & 24.1 & 68.7 \\
\hline Dizziness & 23.5 & 14.8 & 34.6 & 22.2 & 4.9 & 61.7 \\
\hline Nausea/vomiting & 44.4 & 25.9 & 17.3 & 8.6 & 3.7 & 29.6 \\
\hline Sleep disturbance & 7.1 & 6.0 & 19.0 & 29.8 & 38.1 & 86.9 \\
\hline Fatigue & 4.8 & 4.8 & 14.3 & 36.9 & 39.3 & 90.5 \\
\hline Irritability & 9.4 & 23.5 & 27.1 & 27.1 & 12.9 & 67.1 \\
\hline Feeling depressed & 18.8 & 25.9 & 18.8 & 27.1 & 9.4 & \\
\hline Feeling frustrated & 15.3 & 28.2 & 15.3 & 30.6 & 10.6 & 55.3 \\
\hline Poor memory & 21.2 & 20.0 & 23.5 & 27.1 & 8.2 & 58.8 \\
\hline Poor concentration & 11.8 & 21.2 & 32.9 & 22.4 & 11.8 & 67.1 \\
\hline Noise sensitivity & 40.5 & 22.6 & 13.1 & 13.1 & 10.7 & 36.9 \\
\hline Blurred vision & 42.2 & 30.1 & 13.3 & 9.6 & 4.8 & 27.7 \\
\hline Sensitivity to light & 30.5 & 17.1 & 23.2 & 18.3 & 11.0 & 52.5 \\
\hline Double vision & 75.0 & 10.7 & 10.7 & 2.4 & 1.2 & 14.3 \\
\hline Restlessness & 32.1 & 27.4 & 20.2 & 11.9 & 8.3 & 20.4 \\
\hline $\begin{array}{l}\text { Taking longer to } \\
\text { think }\end{array}$ & 25.9 & 30.6 & 16.5 & 20.0 & 7.1 & 43.6 \\
\hline
\end{tabular}

The study was approved by the ethics committee of Umeå University.

\section{Results}

3.1. Pain Intensity. For all patients, the pain intensity on the VAS was $65.8 \pm 20.2 \mathrm{~mm}$. No statistically significant difference was found between women $(65.5 \pm 21.1 \mathrm{~mm})$ and men $(66.8 \pm 18.2 \mathrm{~mm})$.

3.2. Postconcussion Symptoms. The most common PCSs reported were fatigue, sleep disturbance, and poor concentration (Table 1). The most common symptoms rated as a problem were fatigue, sleep disturbance, and headache (Table 2). Statistically significant differences between women 
and men were only found for the symptoms sleep disturbance, feeling frustrated, blurred vision, and taking longer to think (Table 1). No statistically significant difference between men and women was found for the total RPQ score.

3.3. Posttraumatic Stress. The total score of the IES for all patients was $19.3 \pm 15.0$, and the scores for the subscales were avoidance $9.8 \pm 9.1$, and intrusion $9.5 \pm 7.3$. Mild level of posttraumatic stress was reported by $37.2 \%$, moderate stress by $22.1 \%$, and severe stress by $8.1 \%$. No statistically significant differences between men and women were found with respect to total IES (men: $19.7 \pm 13.3$; women: $19.1 \pm$ 15.8), avoidance (men: $10.2 \pm 8.8$; women: $9.6 \pm 9.3$ ), and intrusion (men: $9.5 \pm 5.9$; women: $9.5 \pm 7.8$ ).

3.4. Depression. Depression scores on the HAD for all patients were $6.9 \pm 4.4 \mathrm{~mm}$ (women: $7.4 \pm 4.3$; men: $5.9 \pm$ 3.9). A significantly higher proportion of women $(47.5 \%)$ reported possible-probable depression (HAD score $\geq 8$ ) compared to men $(22.2 \%)(P=0.038)$.

3.5. Correlations. Total score of RPQ was significantly correlated to posttraumatic stress $(r=0.375, P<0.001)$, HAD anxiety $(r=0.455, P<0.001)$, and HAD depression $(r=0.560, P<0.001)$. No significant correlation was found between RPQ and VAS ( $r=0.150, P=0.183)$.

\section{Discussion}

The present study shows that patients with injury-related pain often reported postconcussion symptoms several years after injury. Although more women than men participated in the study, few differences between genders were found. A significant relationship was found between postconcussion symptoms and posttraumatic stress and between postconcussion symptoms and depression and anxiety.

As whiplash is reported as the most common traffic injury, it was not surprising that most patients related their chronic pain condition to a previous whiplash trauma. Previous studies have used several different constructions of questionnaires to ask about postconcussion-like symptoms after whiplash $[14,15]$. Neck pain and headache are the most often reported complaints after whiplash injury, but other symptoms such as dizziness and visual impairments have also been reported [15]. In comparison with a previous follow-up study that also used the RPQ to examine persons five years after whiplash trauma [25], the proportion of the separate symptoms, except for poor concentration, was clearly higher in the present study. The differences may be due to different study populations. Patients in the present study represent a selected group of patients with chronic pain who exhibited severe consequences after their injury and who were referred to a specialist clinic.

The frequencies of symptoms were high and clearly higher than that for MTBI patients who reported on the RPQ from our hospital one year after the trauma [5]. The most common problematic symptoms were headache, fatigue, and sleep disturbance. In a previous study from Canada of MTBIpatients that also used the RPQ, these symptoms were also the most frequently cited both ten days and six weeks after injury [26]. In patients with MTBI and chronic pain, sleep dysfunction is common. Sleep dysfunction is important to assess since sleep dysfunction and fatigue have been shown to aggravate pain and other symptoms [27]. The frequency of cognitive symptoms in the present study was surprisingly high; more than half of the patients described memory and concentration difficulties. Cognitive difficulties are often related to neuropsychological impairments after MTBI, but not all patients are investigated using neuropsychological tests. These patients are screened using self-reported symptoms of memory and concentration dysfunction [6]. In addition, pain has been associated with worse cognitive functioning in persons with a traumatic brain injury (TBI). Pain, posttraumatic stress, and depression all could cause prolonged cognitive impairment after MTBI [15]. In the present study, these factors were also significantly correlated to post-concussion symptoms.

Some limitations of this study should be noted. General practitioners referred patients to a pain rehabilitation clinic because they reported injury-related chronic pain due to an injury sustained more than twelve months since the referral. Thus the results represent a selected group of patients with chronic pain and with severe consequences after the injury.

Although patients reported high frequencies of symptoms, these are seldom assessed in patients with chronic injury-related pain. The results in the present study agree with Smith-Seemiller et al.; they demonstrated that postconcussion symptoms were common in patients with chronic pain [19]. Since several studies have shown a lack of specificity of PCS $[15,28]$, the challenge is to establish a causal link between MTBI and PCS and to the diagnosis post-concussion disorder. According to our findings, the optimization of treatment for PCS requires clinicians to assess postconcussion symptoms, to investigate causes for each patient, and to account for factors such as posttraumatic stress and depression.

\section{References}

[1] J. F. Kraus and P. Nourjah, "The epidemiology of mild head injury," in Mild Head Injury, H. S. Levin, H. M. Eisenberg, and A. L. Benton, Eds., pp. 9-22, Oxford University Press, New York, NY, USA, 1989.

[2] J. Styrke, B. M. Stålnacke, P. Sojka, and U. Björnstig, "Traumatic brain injuries in a well-defined population: epidemiological aspects and severity," Journal of Neurotrauma, vol. 24, no. 9, pp. 1425-1436, 2007.

[3] J. Van Der Naalt, A. H. Van Zomeren, W. J. Sluiter, and J. M. Minderhoud, "One year outcome in mild to moderate head injury: the predictive value of acute injury characteristics related to complaints and return to work," Journal of Neurology Neurosurgery and Psychiatry, vol. 66, no. 2, pp. 207-213, 1999.

[4] E. Johansson, M. Ronnkvist, and A. R. Fugl-Meyer, "Traumatic brain injury in Northern Sweden. Incidence and prevalence of long-standing impairments and disabilities," Scandinavian Journal of Rehabilitation Medicine, vol. 23, no. 4, pp. 179-185, 1991. 
[5] B. M. Stålnacke, U. Björnstig, K. Karlsson, and P. Sojka, "Oneyear follow-up of mild traumatic brain injury: post-concussion symptoms, disabilities and life satisfaction in relation to serum levels of S-100B and neurone-specific enolase in acute phase," Journal of Rehabilitation Medicine, vol. 37, no. 5, pp. 300-305, 2005.

[6] L. J. Carroll, J. D. Cassidy, P. M. Peloso et al., "Prognosis for mild traumatic brain injury: results of the WHO Collaborating Centre Task Force on Mild Traumatic Brain Injury," Journal of Rehabilitation Medicine, Supplement, no. 43, supplement, pp. 84-105, 2004.

[7] WHO, ICD-10: International Statistical Classification of Diseases and Related Health Problems, Tenth Revision, Almqvist \& Wiksell, Uppsala, Sweden, 1997.

[8] American Psychiatric Association, Diagnostical and Statistical Manual of Mental Disorders, American Psychiatric Association, Washington, DC, USA, 1994.

[9] G. Fenton, R. McClelland, A. Montgomery, G. MacFlynn, and W. Rutherford, "The postconcussional syndrome: social antecedents and psychological sequelae," British Journal of Psychiatry, vol. 162, pp. 493-497, 1993.

[10] R. A. Bryant, "Posttraumatic stress disorder and mild brain injury: controversies, causes and consequences," Journal of Clinical and Experimental Neuropsychology, vol. 23, no. 6, pp. 718-728, 2001.

[11] "Pain terms: a list of definitions and notes on usage. Recommended by the IASP subcommittee on taxonomy," Pain, vol. 6, no. 3, pp. 249-252, 1979.

[12] L. Barnsley, S. Lord, and N. Bogduk, "Whiplash injury," Pain, vol. 58, no. 3, pp. 283-307, 1994.

[13] U. Kischka, T. Ettlin, S. Heim, and G. Schmid, "Cerebral symptoms following whiplash injury," European Neurology, vol. 31, no. 3, pp. 136-140, 1991.

[14] T. M. Ettlin, U. Kischka, S. Reichmann et al., "Cerebral symptoms after whiplash injury of the neck: a prospective clinical and neuropsychological study of whiplash injury," Journal of Neurology Neurosurgery and Psychiatry, vol. 55, no. 10, pp. 943-948, 1992.

[15] R. W. Evans, "Persistent post-traumatic headache, postconcussion syndrome, and whiplash injuries: the evidence for a nontraumatic basis with an historical review," Headache, vol. 50, no. 4, pp. 716-724, 2010.

[16] M. P. Alexander, "Mild traumatic brain injury: pathophysiology, natural history, and clinical management," Neurology, vol. 45, no. 7, pp. 1253-1260, 1995.

[17] M. Kyhlbäck, T. Thierfelder, and A. Söderlund, "Prognostic factors in whiplash-associated disorders," International Journal of Rehabilitation Research, vol. 25, no. 3, pp. 181-187, 2002.

[18] E. Williamson, M. Williams, S. Gates, and S. E. Lamb, "A systematic literature review of psychological factors and the development of late whiplash syndrome," Pain, vol. 135, no. 1-2, pp. 20-30, 2008.

[19] L. Smith-Seemiller, N. R. Fow, R. Kant, and M. D. Franzen, "Presence of post-concussion syndrome symptoms in patients with chronic pain vs mild traumatic brain injury," Brain Injury, vol. 17, no. 3, pp. 199-206, 2003.

[20] S. Potter, E. Leigh, D. Wade, and S. Fleminger, "The rivermead post concussion symptoms questionnaire: a confirmatory factor analysis," Journal of Neurology, vol. 253, no. 12, pp. 1603-1614, 2006.

[21] S. V. Scrimshaw and C. Maher, "Responsiveness of visual analogue and McGill pain scale measures," Journal of Manipulative and Physiological Therapeutics, vol. 24, no. 8, pp. 501-504, 2001.
[22] N. S. King, S. Crawford, F. J. Wenden, N. E. G. Moss, and D. T. Wade, "The rivermead post concussion symptoms questionnaire: a measure of symptoms commonly experienced after head injury and its reliability," Journal of Neurology, vol. 242, no. 9, pp. 587-592, 1995.

[23] M. Horowitz, N. Wilner, and W. Alvarez, "Impact of event scale: a measure of subjective stress," Psychosomatic Medicine, vol. 41, no. 3, pp. 209-218, 1979.

[24] A. S. Zigmond and R. P. Snaith, "The hospital anxiety and depression scale," Acta Psychiatrica Scandinavica, vol. 67, no. 6, pp. 361-370, 1983.

[25] D. Merrick and B. M. Stålnacke, "Five years post whiplash injury: symptoms and psychological factors in recovered versus non-recovered," BMC Research Notes, vol. 3, article 190, 2010.

[26] G. Chaput, J. F. Giguère, J. M. Chauny, R. Denis, and G. Lavigne, "Relationship among subjective sleep complaints, headaches, and mood alterations following a mild traumatic brain injury," Sleep Medicine, vol. 10, no. 7, pp. 713-716, 2009.

[27] M. C. Valenza, D. O. Rodenstein, and C. Fernández-de-lasPeñas, "Consideration of sleep dysfunction in rehabilitation," Journal of Bodywork and Movement Therapies, vol. 15, no. 3, pp. 262-267, 2011.

[28] N. S. King, "Post-concussion syndrome: clarity amid the controversy?" British Journal of Psychiatry, vol. 183, pp. 276-278, 2003. 


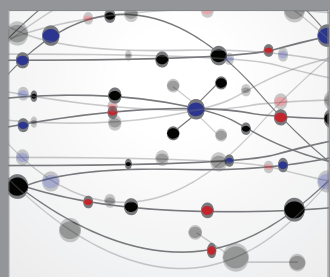

The Scientific World Journal
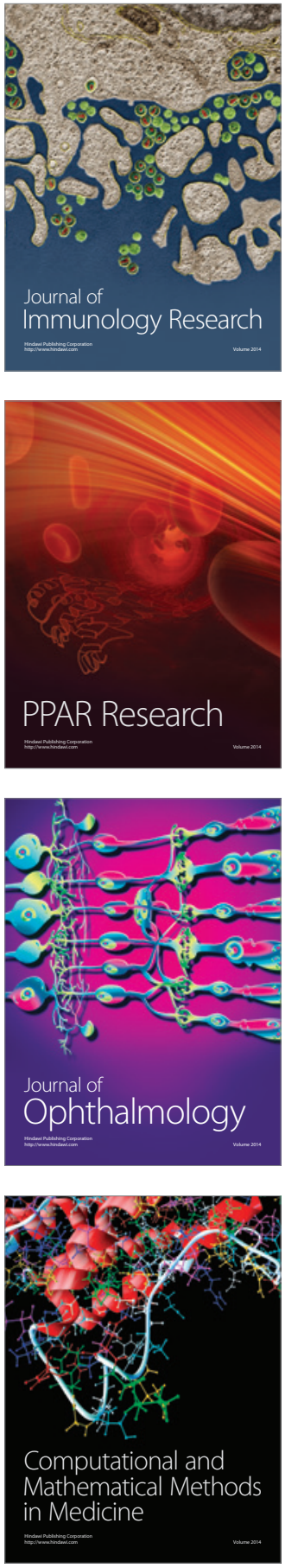

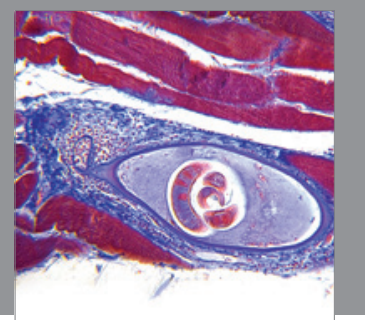

Gastroenterology

Research and Practice
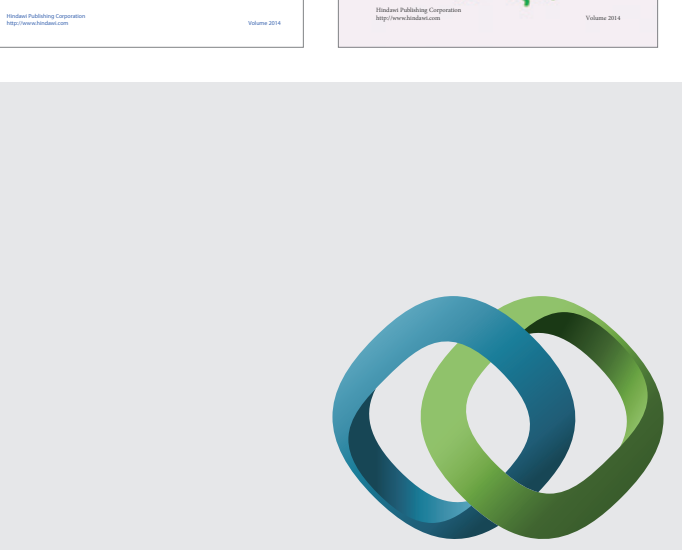

\section{Hindawi}

Submit your manuscripts at

http://www.hindawi.com
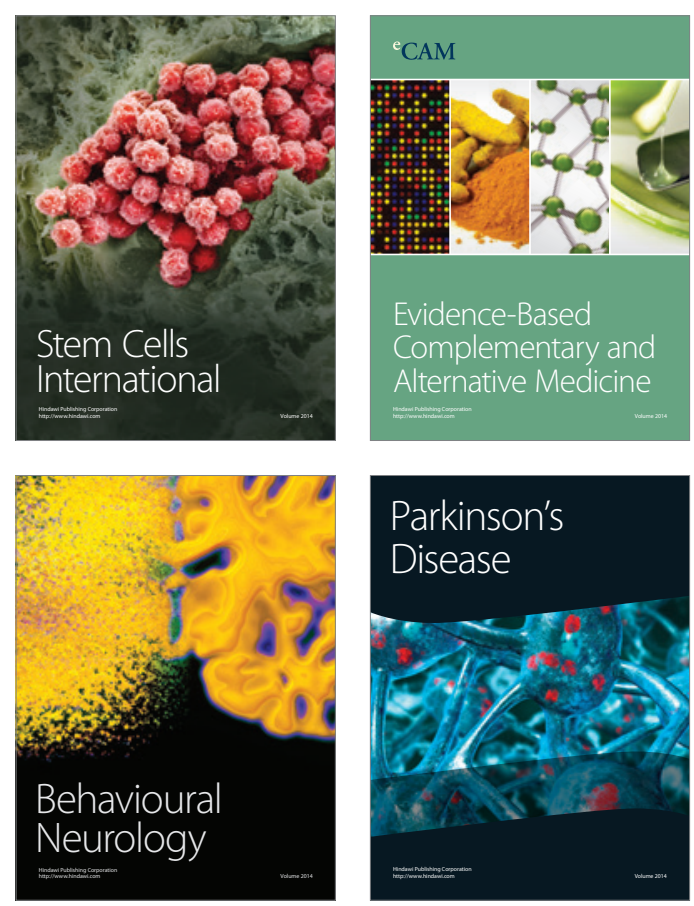

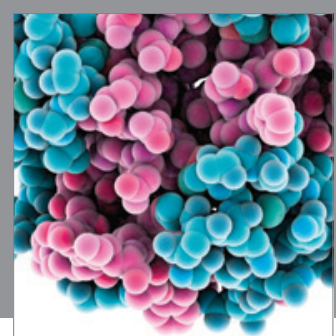

Journal of
Diabetes Research

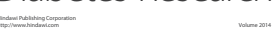

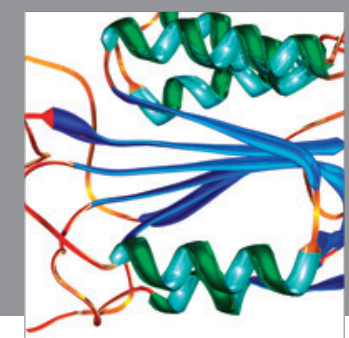

Disease Markers
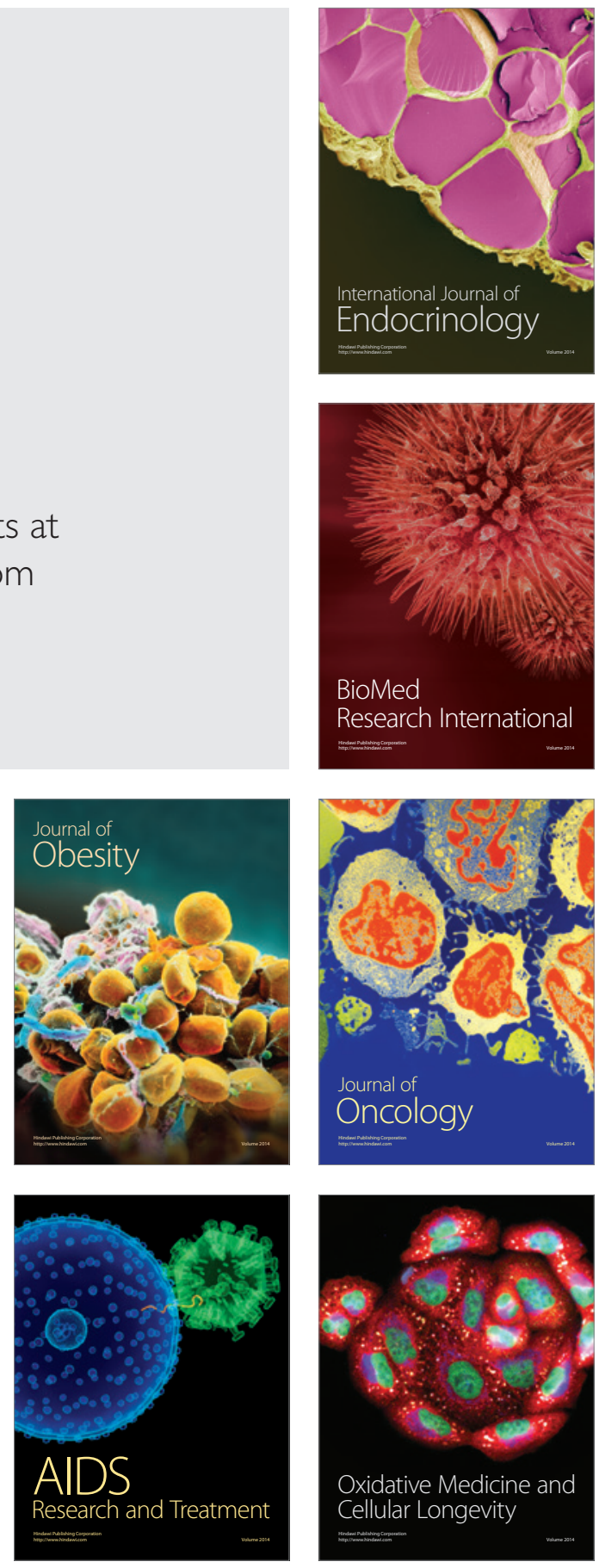